\title{
Different outcomes of experimental leptospiral infection in mouse strains with distinct genotypes
}

\begin{abstract}
Correspondence
Daniel A. Athanazio

daa@ufba.br
\end{abstract}

Received 2 April 2010

Accepted 14 June 2010

\author{
Cleiton S. Santos, ${ }^{1}$ Júlio O. Macedo, ${ }^{1}$ Mauricio Bandeira, ${ }^{2}$ \\ Adenizar D. Chagas-Junior, ${ }^{1}$ Alan J. A. McBride, ${ }^{1}$ Flávia W. C. McBride, ${ }^{2}$ \\ Mitermayer G. Reis ${ }^{1,2}$ and Daniel A. Athanazio ${ }^{2}$ \\ ${ }^{1}$ Gonçalo Moniz Research Centre, Oswaldo Cruz Foundation, Ministry of Health, Salvador, Bahia, \\ Brazil \\ ${ }^{2}$ Federal University of Bahia, Salvador, Bahia, Brazil
}

\section{INTRODUCTION}

Leptospirosis is a widespread zoonosis with a broad clinical spectrum including fatal outcomes due to acute renal failure and pulmonary haemorrhage. Pathogenic leptospires are carried by diverse mammalian reservoirs, and peridomiciliary rodents are the most important source of infection in urban settings (McBride et al., 2005). Despite major efforts to develop new vaccine strategies with a longlasting effect and cross-protection against different serovars, our current knowledge of the immune determinants involved in host protection and pathogenesis remains limited (McBride et al., 2005).

Diverse experimental animal models are used in leptospirosis research. Guinea pigs and hamsters are the most suitable laboratory rodents for reproducing acute lethal infection (Nally et al., 2004; Silva et al., 2008; Spichler et al., 2007), whereas rats represent a prototype of resistance to acute disease and a potential model for persistent infection (Athanazio et al., 2008b; Nally et al., 2005b). Mice usually develop a persistent asymptomatic carrier state and are therefore recognized as resistant hosts, although this has not been studied in detail in a broad range of mouse strains. Swiss mice may succumb or develop subclinical

Abbreviations: MAT, microscopic agglutination test; p.i., post-infection. renal colonization depending on their age and on inoculum size (Faine, 1962). Mouse models have the advantage that a broad array of immunological and genetic tools is available for basic research. Several studies on transgenic and/or mutant mouse strains have been carried out (Athanazio et al., 2008a; Nally et al., 2005a; Viriyakosol et al., 2006); however, the wider use of such tools is hampered by a lack of understanding of the outcome of experimental leptospiral infection among the different mouse strains. For instance, the lack of effect of a single gene knockout (such as interleukin-4 in BALB/c mice) could be due potentially to an intrinsic resistance to the disease in wild-type mice (Athanazio et al., 2008a). In addition, the induction of higher expression levels of proinflammatory mediators in murine renal tubular cells in vitro implicates leptospire-derived products in interstitial nephritis (Yang et al., 2000, 2002, 2006). This view ignores the fact that interstitial nephritis is a late feature of human leptospirosis, probably reflecting secondary lesions following acute tubular damage (Arean, 1962). Also, it is not known to what extent mice develop interstitial nephritis after experimental leptospiral infection. In a previous report, we observed mild inflammatory changes in convalescent $\mathrm{C} 57 \mathrm{BL} / 6$ mice, whereas the BALB/c strain failed to exhibit any subclinical pathology (Athanazio et al., 2008a). 
The aim of this study was to clarify the outcome of experimental leptospiral infection among four commonly used laboratory mouse strains. We tested low and high infective doses of a highly virulent Leptospira interrogans serogroup Icterohaemorrhagiae isolate and investigated five end points of infection: survival, renal pathology, renal colonization in the convalescent phase by immunofluorescence of imprint samples (Chagas-Junior et al., 2009), immune responses by microscopic agglutination test (MAT) and an in-house IgG ELISA.

\section{METHODS}

Leptospira strain and culture conditions. Leptospires were cultivated in liquid Ellinghausen-McCullough-Johnson-Harris (EMJH) medium (Difco Laboratories) at $29{ }^{\circ} \mathrm{C}$ and counted in a Petroff-Hausser counting chamber (Fisher Scientific). An isolate from Brazil, L. interrogans serogroup Icterohaemorrhagiae strain Cop, was used in all assays. This strain was passaged and reisolated from hamsters four times and stored at $-70{ }^{\circ} \mathrm{C}$. Frozen aliquots were thawed and passaged in liquid medium 14 times prior to use as a lowpassage-number isolate in the infection experiments. In previous experiments, the virulence of this strain at this passage was evaluated in hamsters and the $50 \%$ lethal dose was calculated to be $\sim 164$ leptospires.

Experimental infection of mouse models of leptospirosis. Four groups of wild-type mice strains (A, CBA, BALB/c and C57BL/6) were infected intraperitoneally with a low $\left(10^{3}\right)$ or a high $\left(10^{6}\right)$ infective dose of $L$. interrogans serogroup Icterohaemorrhagiae strain Cop. Control groups were inoculated with $1 \mathrm{ml}$ sterile EMJH medium. All animals were females; the $\mathrm{A}, \mathrm{BALB} / \mathrm{c}$ and $\mathrm{C} 57 \mathrm{BL} / 6$ strains were $4-5$ weeks old, whilst the CBA strain mice were $6-7$ weeks old. The A strain used in this study refers to the A/J Unib substrain derived from the $\mathrm{A} / \mathrm{J}$ strain and maintained at Cemib (Multidisciplinary Centre for Biological Research), University of Campinas, Brazil. The same institution was the source of the CBA and $\mathrm{BALB} / \mathrm{c}$ mice used in this study, whilst the C57BL/6 mice were supplied by CAECAL (Laboratory Animal Breeding Centre), Oswaldo Cruz Foundation (Fiocruz). All four strains were originally purchased from The Jackson Laboratory.

Light microscopy. Euthanasia was performed on animals at 28 days post-infection (p.i.) and necropsies were carried out immediately following euthanasia. One kidney was fixed in $4 \%$ formalin, embedded in paraffin and sections of $4-5 \mu \mathrm{m}$ were used for conventional histology. A semi-quantitative estimation of interstitial nephritis was used with the following criteria: grade + , infiltrates rich in macrophages and lymphocytes restricted to periarterial areas; grade ++ , infiltrates extending to other renal parenchymal zones with one to two lesions per field of view at $\times 400$ magnification; and grade +++ , the same lesion was detected in more than two areas per field of view at $\times 400$ magnification (Athanazio et al., 2008a). Grade ++ and +++ lesions were considered to be severe for analysis purposes.

Immunofluorescence of imprint samples. Imprints were obtained by direct pressure of the cut surface of the kidney sample onto a polyL-lysine-coated glass slide as described previously (Chagas-Junior et al., 2009). Briefly, the imprint slides were dried at room temperature, fixed in acetone for $3 \mathrm{~min}$ and the smear regions on the slides were demarcated with a hydrophobic barrier pen. Imprint slides were incubated for $60 \mathrm{~min}$ with a primary rabbit polyclonal anti-leptospiral antibody at a dilution of $1: 200$. After three washes in PBS, the imprints were incubated with goat anti-rabbit IgG-FITC conjugate at a dilution of $1: 500$, washed three times in PBS and dried before visualization of stained organisms by fluorescence microscopy. Kidney samples from non-infected mice were used as negative controls. Counterstaining of nucleic acids or cell cytoplasm was achieved with $1 \mathrm{mg} 4^{\prime}$,6-diamidino-2-phenylindole $\mathrm{ml}^{-1}$ (SigmaAldrich) at room temperature for $10 \mathrm{~min}$ or with $0.1 \%$ Evans Blue (Sigma Aldrich), respectively. Leptospires were quantified in imprint samples as the mean number of leptospires in 10 fields of view at a magnification of $\times 400$. Only intact spiral-shaped organisms were included in the calculation.

Serology assays. The MAT was performed as described previously (WHO, 2003) except that only the L. interrogans serogroup Icterohaemorrhagiae serovar Copenhageni reference strain M20 was used as the live antigen.

Cells from 7-day-old cultures of L. interrogans serogroup Icterohaemorrhagiae strain Cop were harvested by centrifugation $\left(1500 \mathrm{~g}\right.$ for $30 \mathrm{~min}$ at $4{ }^{\circ} \mathrm{C}$ ) and washed three times by centrifugation in PBS. The cells were resuspended in $0.1 \mathrm{M} \mathrm{Na}_{2} \mathrm{CO}_{3}$ (pH 9.6), at a concentration of approximately $10^{8}$ cells $\mathrm{ml}^{-1}$. The cells were inactivated by heating at $56{ }^{\circ} \mathrm{C}$ for $20 \mathrm{~min}$. The resulting material was stored at $-20{ }^{\circ} \mathrm{C}$ and used as the antigen for ELISA. An in-house IgG ELISA was used to compare anti-Leptospira IgG levels among the various mouse strains used in this study. The optimal concentrations of the antigen, mouse sera and antibody conjugates were determined in a preliminary chequerboard analysis. The equivalent of $\sim 10^{7}$ inactivated whole leptospires ( $L$. interrogans serogroup Icterohaemorrhagiae strain Cop) in $100 \mu \mathrm{l} 0.1 \mathrm{M} \mathrm{Na}_{2} \mathrm{CO}_{3}$ $(\mathrm{pH}$ 9.6) was adsorbed onto the surface of each microtitre well at

Table 1. Presence of nephritis, leptospiral count and MAT titres in mice at 28 days p.i.

QD, Quartile deviation; ID, infective dose.

\begin{tabular}{|c|c|c|c|c|c|c|c|}
\hline \multirow[t]{2}{*}{ Mouse strain } & \multicolumn{3}{|c|}{$\%$ Nephritis (no./total)* } & \multicolumn{2}{|c|}{ Leptospiral count $($ mean $\pm \mathrm{SD})$} & \multicolumn{2}{|c|}{ MAT titre (median $\pm \mathrm{QD})$} \\
\hline & Control & Low ID & High ID & Low ID & High ID & Low ID & High ID \\
\hline A & $0(0 / 20)$ & $66.7(10 / 15) \dagger$ & $40.0(8 / 20) \dagger$ & $20 \pm 16$ & $26 \pm 21$ & $800 \pm 800$ & $800 \pm 1200$ \\
\hline CBA & $0(0 / 20)$ & $78.9(15 / 19) \dagger$ & $60.0(12 / 20) \dagger$ & $10 \pm 11$ & $10 \pm 10$ & $1200 \pm 900$ & $800 \pm 300$ \\
\hline $\mathrm{BALB} / \mathrm{c}$ & $0(0 / 19)$ & $0(0 / 20)$ & $0(0 / 20)$ & $5 \pm 9$ & $5 \pm 7$ & $400 \pm 200$ & $200 \pm 300$ \\
\hline $\mathrm{C} 57 \mathrm{BL} / 6$ & $0(0 / 20)$ & $90.0(27 / 30) \dagger$ & $92.0(23 / 25) \dagger$ & $19 \pm 27$ & $15 \pm 16$ & $800 \pm 600$ & $800 \pm 400$ \\
\hline
\end{tabular}

${ }^{\star}$ Histopathological evidence for interstitial nephritis, grade + or ++ (see Table 2 for further details).

$\dagger P<0.01$ compared with the uninfected control group. 
Table 2. Level and severity of interstitial nephritis in infected mice at 28 days p.i.

Grade: + , mild lesions; ++ , moderate lesions; +++ , severe lesions.

\begin{tabular}{|c|c|c|c|c|c|c|c|c|c|}
\hline Mouse strain & \multicolumn{3}{|c|}{ Uninfected controls } & \multicolumn{3}{|c|}{ Low infective dose } & \multicolumn{3}{|c|}{ High infective dose } \\
\hline A & $0(0 / 20)$ & $0(0 / 20)$ & $0(0 / 20)$ & $53.3(8 / 15)$ & $13.3(2 / 15)$ & $0(0 / 15)$ & $40.0(8 / 20)$ & $0(0 / 20)$ & $0(0 / 20)$ \\
\hline CBA & $0(0 / 20)$ & $0(0 / 20)$ & $0(0 / 20)$ & $47.4(9 / 19)$ & $31.6(6 / 19)$ & $0(0 / 19)$ & $50.0(10 / 20)$ & $10.0(2 / 20)$ & $0(0 / 20)$ \\
\hline
\end{tabular}

$37{ }^{\circ} \mathrm{C}$ for $1 \mathrm{~h}$. The wells were washed five times with $0.05 \%$ Tween 20 in PBS (PBS-T) and incubated for $1 \mathrm{~h}$ at $37{ }^{\circ} \mathrm{C}$ with $200 \mu \mathrm{l}$ blocking solution (PBS-T plus 1\% BSA). Mouse serum diluted 1:200 in blocking solution was added and incubated for $1 \mathrm{~h}$ at $37{ }^{\circ} \mathrm{C}$. After five washes with PBS-T, anti-mouse horseradish peroxidase-conjugated antibody ( $1: 2000$; Dako Cytomation) was added and incubated for $1 \mathrm{~h}$ at $37^{\circ} \mathrm{C}$. After five washes with PBS, $100 \mu \mathrm{l}$ substrate solution

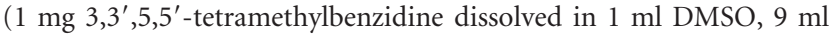
$0.05 \mathrm{M}$ phosphate citrate buffer, $2 \mu \mathrm{l} 30 \% \mathrm{H}_{2} \mathrm{O}_{2}$ ) was added to each well. The colour reaction was allowed to proceed for $15 \mathrm{~min}$ and stopped with $25 \mu \mathrm{l} 1 \mathrm{M} \mathrm{H}_{2} \mathrm{SO}_{4}$. The plate was read in a microplate reader (GENios; Tecan) at $A_{450}$.

Statistics. Statistical analyses were performed using the GraphPad Prism 4.03 software package. Categorical data were compared by Fisher's exact test and numerical data were compared using a nonparametric Mann-Whitney test (two groups) or a Kruskal-Wallis test (more than two groups).

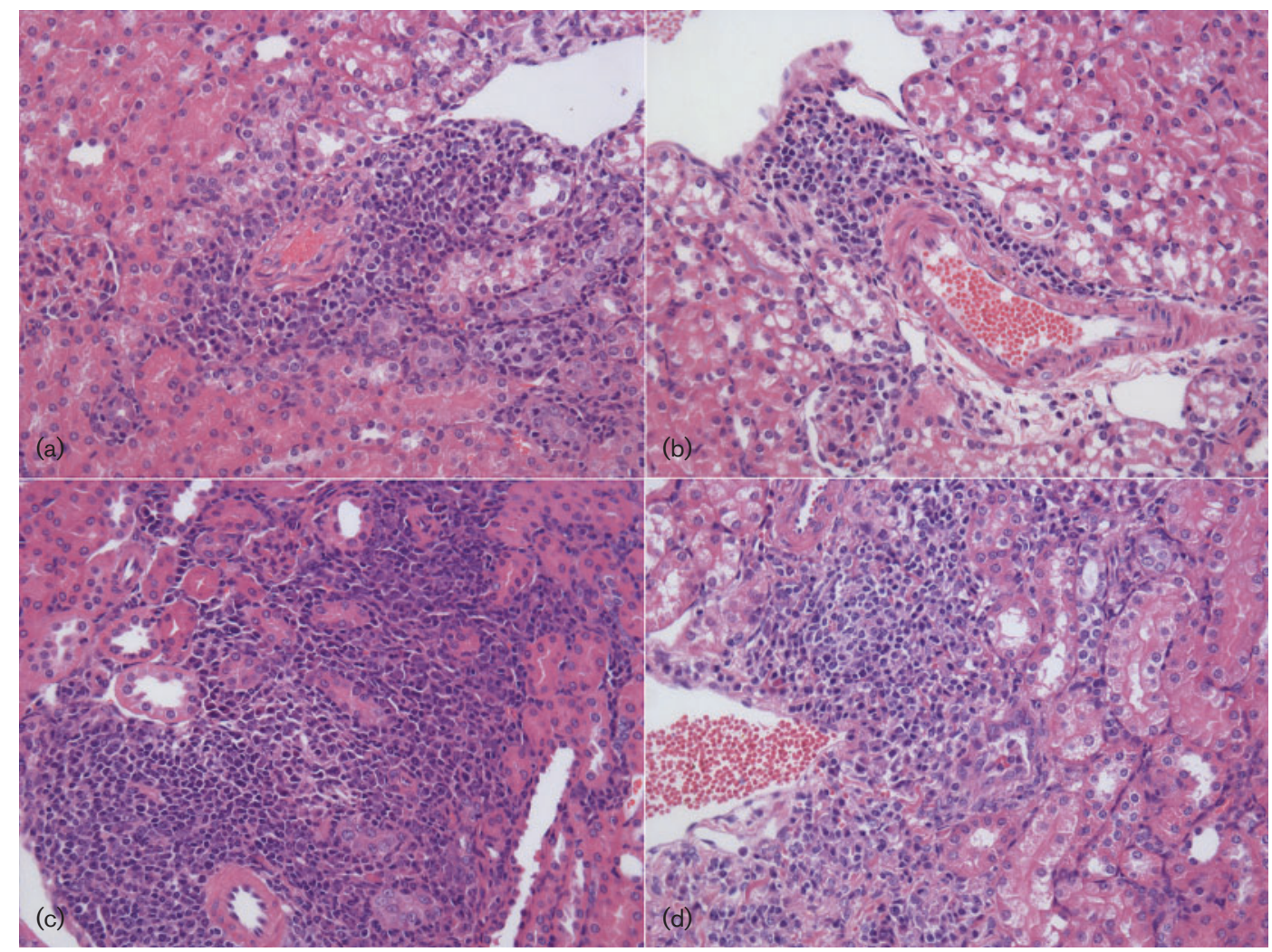

Fig. 1. Illustrative images of interstitial nephritis grading in infected mice. (a, b) Kidney sample from a C57BL/6 mouse infected with a low infective dose $\left(10^{3}\right.$ leptospires) exhibiting nephritis grade + , characterized by infiltrates rich in macrophages and lymphocytes restricted to periarterial areas. (c, d) Kidney sample from a C57BL/6 mouse infected with a low infective dose exhibiting nephritis grade ++ , characterized by inflammatory infiltrates extending to other renal parenchymal zones. Magnification, $\times 400$. 


\section{RESULTS}

None of the infected or control (uninfected) animals exhibited any clinical symptoms of leptospirosis; therefore, they were euthanized and necropsied at 28 days p.i. Kidney samples were examined microscopically for evidence of interstitial nephritis. None of the control animals, regardless of the mouse strain, exhibited lesions. Of note, none of the infected $\mathrm{BALB} / \mathrm{c}$ mice, regardless of the size of the infective dose, exhibited inflammatory lesions. Table 1 summarizes the frequency of interstitial nephritis observed. The A, CBA and C57BL/6 strains presented with significantly more lesions than the controls $(P<0.01)$ for both the lower and higher infective doses. However, the size of the infective dose in these strains had no significant effect on the frequency of interstitial nephritis observed. Detailed information on the severity of interstitial nephritis and the infective dose is presented in Table 2. Illustrative images of the interstitial nephritis grades + and ++ observed in this study are shown in Fig. 1.

The number of leptospires in kidney samples collected from the mouse strains at 28 days p.i. was determined by immunofluorescence-based detection in imprint samples (Table 1). No spirochaetes were detected in the uninfected controls. Strains A, CBA and C57BL/6 exhibited significantly higher $(P<0.001)$ loads of leptospires compared with the BALB/c infected groups. This difference was observed for both infective doses used in this study. Significantly higher numbers of leptospires were detected in the A strain at the higher infective dose. Interestingly, the inverse was observed in the C57BL/6 strain, where a significantly higher leptospire count was seen in the group that received the lower infective dose. Representative images of the immunofluorescence-based detection of leptospires in imprint samples from mouse kidney samples are show in Fig. 2.

MAT quantification of agglutination antibodies against serovar Copenhageni is presented in Table 1. This revealed lower titres $(1: 400$ and $1: 200)$ in the $B A L B / c$ groups, regardless of the size of the infective dose. In the other mouse strains, the median MAT titres were significantly higher and ranged from $1: 800$ to $1: 1200$. However, there was considerable variation of the MAT titres within the individual groups, as reflected in the quartile deviations presented in Table 1. The specific anti-leptospiral IgG levels in the infected mice strains were determined by ELISA (Fig. 3). The IgG levels were significantly higher in the infected animals than in the control groups. In the A and $\mathrm{BALB} / \mathrm{c}$ strains, the higher infective dose stimulated significantly higher IgG levels $(P<0.05)$ compared with the lower infective dose. When the $\operatorname{IgG}$ responses between strains were compared, the C57BL/6 mice, at the lower infective dose, exhibited significantly higher IgG levels $(P<0.01)$, and the BALB/c mice, at the higher infective dose, had significantly higher IgG levels $(P<0.05)$ (Fig. 3).

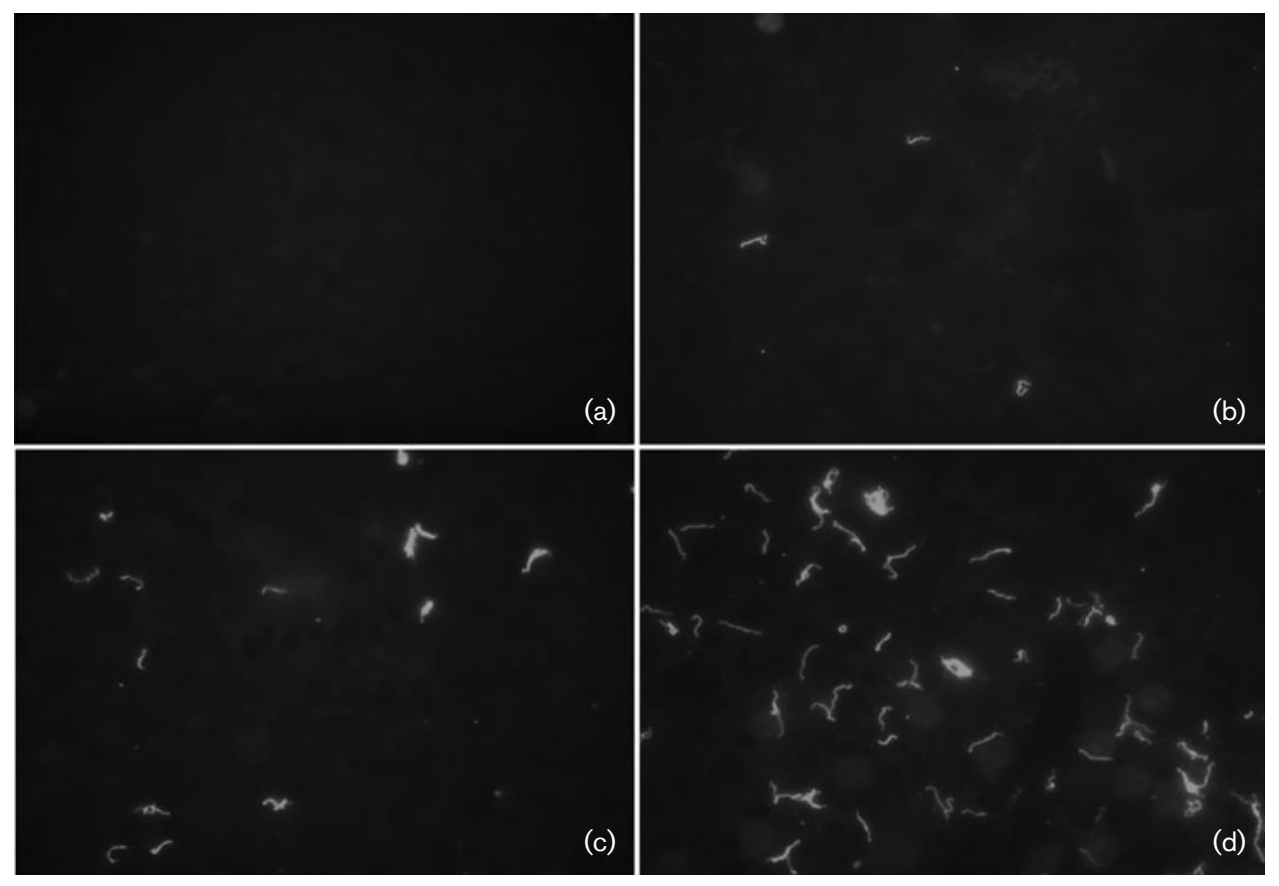

Fig. 2. Illustrative images of immunofluorescence-based detection of leptospires in imprint samples from representative mouse kidneys. (a) An A strain mouse inoculated with sterile EMJH medium (uninfected control). (b) BALB/c mouse infected with a low infective dose $\left(10^{3}\right.$ leptospires): $\sim 3$ leptospires per $\times 400$ field of view. (c) A CBA strain mouse infected with a low infective dose: $\sim 12$ leptospires per $\times 400$ field of view. (d) An A strain mouse infected with a low infective dose: $\sim 46$ leptospires per $\times 400$ field of view. Magnification, $\times 400$. 


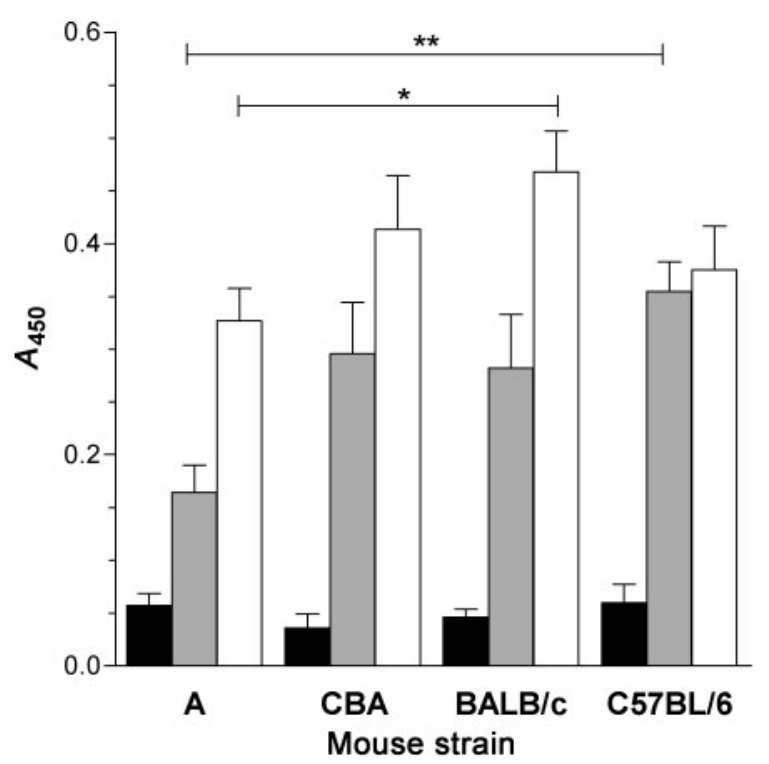

Fig. 3. Analysis of serum anti-leptospiral lgG levels in infected mice at 28 days p.i. An ELISA was used to determine lgG levels in sera collected from a control (uninfected) group (filled bars), a low infective dose $\left(10^{3}\right.$ leptospires) group (shaded bars) and a high infective dose ( $10^{6}$ leptospires) group of mice (open bars). Results are shown as means \pm SEM for each group. The statistical significance between groups was calculated using a MannWhitney test: ${ }^{*}, P<0.05 ;{ }^{*}, P<0.01$.

\section{DISCUSSION}

Based on our observations in this study, the general concept that mice are relatively resistant to severe leptospirosis appears to hold true for many of the widely used laboratory strains. As expected, none of the mouse strains proved to be a model of lethal leptospirosis. However, our results indicated that certain strains could be useful for studies of experimental leptospirosis. The A and C57BL/6 mouse strains exhibited significantly higher leptospiral loads in kidney samples, and this may prove advantageous when studying Leptospira species recovered from renal tubules, as large numbers of leptospires are required in such studies. The A, CBA and C57BL/6 strains tended to develop more inflammatory lesions, suggesting that they may be the most suitable strains for studies on interstitial nephritis. Furthermore, the C57BL/6 strain displayed significantly more kidney lesions at the high infective dose than any of the other strains (Tables 1 and 2). This is in agreement with a previous study, where we reported higher susceptibility in the C57BL/6 strain compared with the BALB/c strain (Athanazio et al., 2008a).

Our data on the immune responses support only preliminary interpretations; however, it is interesting to note that the A strain displayed one of the highest leptospiral loads observed in the kidneys and significantly lower levels of specific anti-Leptospira IgG. In contrast, BALB/c mice exhibited both significantly fewer kidney lesions (zero) and a lower leptospiral load (independent of the infective dose), together with high levels of $\mathrm{IgG}$, significantly so when compared with the A strain at the higher infective dose. Furthermore, the IgG response in both of these strains was dose dependent (Fig. 3). In addition, significantly higher levels of IgG were observed in the C57BL/6 strain compared with the A strain at the lower infective dose. Leptospiral load in the kidneys of both of these strains was comparable and, although the frequency of interstitial nephritis was higher in the C57BL/6 strain, it was not significant at the lower infective dose (Table 1). However, it was significant when only severe nephritis (grade ++ ) was evaluated at both the low and high infective dose when comparing the A and C57BL/6 strains (Table 2). It is possible that the lower MAT titres observed in the $\mathrm{BALB} / \mathrm{c}$ strain may be due to the rapid clearance of leptospires during the initial stages of infection. However, the IgG levels observed in the BALB/c groups seem to contradict this conclusion.

Experimental data on leptospiral infection in mice are sporadic and fragmented. Passive immunization experiments and transfer of splenic B cell subsets in cyclophosphamide-treated $\mathrm{BALB} / \mathrm{c}$ mice have suggested that humoral immunity is the key issue in natural resistance to disease. Athymic nude mice showed no difference in susceptibility when compared with wild-type animals (Adler \& Faine, 1977). Transgenic and mutant murine models have been used to study leptospirosis, yet most studies have explored only the role of innate immunity. Toll-like receptor (TLR)-4 defective $\mathrm{C} 3 \mathrm{H} / \mathrm{HeJ}$ mice have been used to evaluate recombinant protein vaccine candidates (Koizumi \& Watanabe, 2004). Double-knockout (TLR2 and TLR4) C57BL/6 mice were also found to be highly susceptible to lethal disease (Chassin et al., 2009). TLR2-defective C57BL/6 mice were found to be resistant to the toxic effects of leptospiral LPS, but the role of TLR2 in host innate protection was not evaluated (Werts et al., 2001). Furthermore, severe combined immunodeficiency $\mathrm{C} 3 \mathrm{H}$ and $\mathrm{C} 3 \mathrm{H} / \mathrm{HeJ}$ mice are highly susceptible to lethal infection (Nally et al., 2005a; Viriyakosol et al., 2006). Recently, the $\mathrm{BALB} / \mathrm{c}$ and $\mathrm{C} 3 \mathrm{H} / \mathrm{HeJ}$ strains were used as models of resistance and susceptibility, respectively (da Silva et al., 2009). Similar results for wild-type mice have been reported for leishmaniasis, where a C57BL/6 strain was resistant whilst $\mathrm{BALB} / \mathrm{c}$ mice were susceptible to infection (Barral-Netto et al., 1987).

Our results indicate recommended strains for future research in experimental leptospirosis. Among those tested, the A strain may be the strain of choice for studies aiming to recover large numbers of leptospires from colonized kidneys. Mouse strains CBA and C57BL/6 most frequently developed inflammatory lesions and would be the most suitable for studies on leptospirosis-associated interstitial nephritis. BALB/c mice are the strain of choice for studying mechanisms that involve innate immunity and/or rapidly adaptive immune responses. Additionally, the availability of a wide range of genetically manipulated mouse strains 
opens a wide range of possibilities for analysing leptospiral pathogenesis.

\section{ACKNOWLEDGEMENTS}

This work was supported by the Research Support Foundation for the State of Bahia (FAPESB), grants PES-0092/2008 and APP0057/2009, and the Oswaldo Cruz Foundation. The authors are grateful to Luciane Marieta Soares for technical assistance in the experimental procedures.

\section{REFERENCES}

Adler, B. \& Faine, S. (1977). Host immunological mechanisms in the resistance of mice to leptospiral infections. Infect Immun 17, 6772.

Arean, V. M. (1962). The pathologic anatomy and pathogenesis of fatal human leptospirosis (Weil's disease). Am J Pathol 40, 393423.

Athanazio, D. A., Santos, C. S., Santos, A. C., McBride, F. W. C. \& Reis, M. G. (2008a). Experimental infection in tumor necrosis factor alpha, interferon gamma and interleukin 4 deficient mice by pathogenic Leptospira interrogans. Acta Trop 105, 95-98.

Athanazio, D. A., Silva, E. F., Santos, C. S., Rocha, G. M., VannierSantos, M. A., McBride, A. J. A., Ko, A. I. \& Reis, M. G. (2008b). Rattus norvegicus as a model for persistent renal colonization by pathogenic Leptospira interrogans. Acta Trop 105, 176-180.

Barral-Netto, M., Cardoso, S. A. \& Barral, A. (1987). Different patterns of disease in two inbred mouse strains infected with a clone of Leishmania mexicana amazonensis. Acta Trop 44, 5-11.

Chagas-Junior, A. D., McBride, A. J., Athanazio, D. A., Figueira, C. P., Medeiros, M. A., Reis, M. G., Ko, A. I. \& McBride, F. C. (2009). An imprint method for detecting leptospires in the hamster model of vaccine-mediated immunity for leptospirosis. J Med Microbiol 58, 1632-1637.

Chassin, C., Picardeau, M., Goujon, J. M., Bourhy, P., Quellard, N., Darche, S., Badell, E., d'Andon, M. F., Winter, N. \& other authors (2009). TLR4- and TLR2-mediated B cell responses control the clearance of the bacterial pathogen, Leptospira interrogans. J Immunol 183, 2669-2677.

da Silva, J. B., Ramos, T. M., de Franco, M., Paiva, D., Ho, P. L., Martins, E. A. \& Pereira, M. M. (2009). Chemokines expression during Leptospira interrogans serovar Copenhageni infection in resistant BALB/c and susceptible C3H/HeJ mice. Microb Pathog 47, 87-93.

Faine, S. (1962). The growth of Leptospira australis B in the kidneys of mice in the incipient experimental carrier state. J Hyg (Lond) 60, 435442.
Koizumi, N. \& Watanabe, H. (2004). Leptospiral immunoglobulin-like proteins elicit protective immunity. Vaccine 22, 1545-1552.

McBride, A. J., Athanazio, D. A., Reis, M. G. \& Ko, A. I. (2005). Leptospirosis. Curr Opin Infect Dis 18, 376-386.

Nally, J. E., Chantranuwat, C., Wu, X. Y., Fishbein, M. C., Pereira, M. M., Da Silva, J. J., Blanco, D. R. \& Lovett, M. A. (2004). Alveolar septal deposition of immunoglobulin and complement parallels pulmonary hemorrhage in a guinea pig model of severe pulmonary leptospirosis. Am J Pathol 164, 1115-1127.

Nally, J. E., Fishbein, M. C., Blanco, D. R. \& Lovett, M. A. (2005a). Lethal infection of $\mathrm{C} 3 \mathrm{H} / \mathrm{HeJ}$ and $\mathrm{C} 3 \mathrm{H} / \mathrm{SCID}$ mice with an isolate of Leptospira interrogans serovar Copenhageni. Infect Immun 73, 70147017.

Nally, J. E., Chow, E., Fishbein, M. C., Blanco, D. R. \& Lovett, M. A. (2005b). Changes in lipopolysaccharide $\mathrm{O}$ antigen distinguish acute versus chronic Leptospira interrogans infections. Infect Immun 73, 3251-3260.

Silva, E. F., Santos, C. S., Athanazio, D. A., Seyffert, N., Seixas, F. K., Cerqueira, G. M., Fagundes, M. Q., Brod, C. S., Reis, M. G. \& other authors (2008). Characterization of virulence of Leptospira isolates in a hamster model. Vaccine 26, 3892-3896.

Spichler, A., Ko, A. I., Silva, E. F., de Brito, T., Silva, A. M., Athanazio, D., Silva, C. \& Seguro, A. (2007). Reversal of renal tubule transporter down-regulation during severe leptospirosis with antimicrobial therapy. Am J Trop Med Hyg 77, 1111-1119.

Viriyakosol, S., Matthias, M. A., Swancutt, M. A., Kirkland, T. N. \& Vinetz, J. M. (2006). Toll-like receptor 4 protects against lethal Leptospira interrogans serovar Icterohaemorrhagiae infection and contributes to in vivo control of leptospiral burden. Infect Immun 74, 887-895.

Werts, C., Tapping, R. I., Mathison, J. C., Chuang, T.-H., Kravchenko, V., Saint Girons, I., Haake, D. A., Godowski, P. J., Hayashi, F. \& other authors (2001). Leptospiral lipopolysaccharide activates cells through a TLR2-dependent mechanism. Nat Immunol 2, 346-352.

WHO (2003). Serological techniques (MAT and ELISA). In Human Leptospirosis: Guidance for Diagnosis, Surveillance and Control, pp. 6366. Malta: World Health Organization.

Yang, C.-W., Wu, M.-S., Pan, M.-J., Hong, J.-J., Yu, C.-C., Vandewalle, A. \& Huang, C.-C. (2000). Leptospira outer membrane protein activates $\mathrm{NF}-\kappa \mathrm{B}$ and downstream genes expressed in medullary thick ascending limb cells. J Am Soc Nephrol 11, 2017-2026.

Yang, C.-W., Wu, M.-S., Pan, M.-J., Hsieh, W.-J., Vandewalle, A. \& Huang, C.-C. (2002). The leptospira outer membrane protein LipL32 induces tubulointerstitial nephritis-mediated gene expression in mouse proximal tubule cells. J Am Soc Nephrol 13, 2037-2045.

Yang, C.-W., Hung, C.-C., Wu, M.-S., Tian, Y.-C., Chang, C.-T., Pan, M.-J. \& Vandewalle, A. (2006). Toll-like receptor 2 mediates early inflammation by leptospiral outer membrane proteins in proximal tubule cells. Kidney Int 69, 815-822. 